\title{
Modeling hydrological consequences of climate and land use change - Progress and Challenges
}

\author{
Jan Feyen, Raúl F. Vázquez Zambrano \\ Dirección de Investigación de la Universidad de Cuenca (DIUC), Cuenca, Ecuador \\ Autor para correspondencia: jan.feyen@biw.kuleuven.be \\ Fecha de recepción: 1 de agosto de 2011 - Fecha de aceptación: 15 de octubre de 2011
}

\section{RESUMEN}

Este artículo resume el estado del arte en relación a la modelación hidrológica y su capacidad de predecir los efectos del cambio climático y del uso de la tierra sobre el ciclo hidrológico. En conclusión, se abordan los retos investigativos que la comunidad científica debería considerar para poder observar y modelar, a escala regional, el ciclo hidrometeorológico en respuesta a los cambios de origen antropogénico sobre el clima y el uso de la tierra. Los resultados presentados en este documento son el producto de una extensa revisión de literatura científica y de la experiencia personal de los autores. Dado que el enfoque principal de este artículo es el de modelación hidrológica, muchos otros aspectos tales como las buenas prácticas de la gestión integrada de los recursos hídricos, la gobernabilidad transfronteriza de las aguas, el establecimiento de marcos de trabajo institucionales, la potenciación de las comunidades locales para su participación efectiva en la gestión del agua y en la formulación de políticas, entre muchos otros aspectos muy relevantes, no se consideran en este artículo para evitar que el enfoque del mismo se diluya de manera innecesaria.

Palabras clave: Modelación hidrológica, cambio climático, cambio del uso de la tierra, retos de investigación, revisión extensa de literatura.

\begin{abstract}
This paper provides the state-of-the-art in hydrologic modeling regarding its capability of predicting the effects of climate and land use change on the hydrological cycle. In conclusion, the research challenges are pinpointed, which the community should address as to be able to observe and model, at a regional-scale, the coupled climate-water cycle in response to the human induced changes in climate and land use. The findings presented herein are a compilation resulting from an extensive literature review and the personal expertise of the authors. Given the focus on hydrologic modeling, many other aspects such as the best practices of integrated water resources management, cross-boundary water governance, the establishment of institutional frameworks, empowerment of local communities to participate effectively in water management and policy making, among many other very relevant aspects, were intentionally not considered as not to dilute the focus of the paper.
\end{abstract}

Keywords: Hydrologic modeling, climate change, land use change, research challenges, extensive literature survey.

\section{INTRODUCTION}

A question to reflect on is "Why is modeling of the hydrological consequences of climate and land use change so important?" According to Sanderson et al. (2002) the most obvious reason is that human activities now produce geologic-scale impacts which are deepening and widening across the planet. Signs of this footprint are declining snowpacks resulting from human-induced climate change 
(Barnett et al., 2008), quickly shrinking aquifer storages due to excessive pumping (Rodell et al., 2009), significant distortion of river flow regimes due to the building of dams (Poff et al., 2007), altered groundwater recharge due to changes in land use (Scanlon et al., 2006), among many other manifestations. The triggering factor in all this is the growing population resulting in an increased consumption of energy, water, food, and living space, radically altering our environment. As stated by Palmer et al. (2004) and Wagener et al. (2008) many of our freshwater services are becoming irretrievably degraded. The cumulative consequence of growing demand and a shrinking resource base is increased competition for earth's natural resources, such as water, oil, minerals, etc. Parallel with the decline in freshwater resources, the society is increasingly confronted with hydrological hazards such as floods and droughts, not only in the least resilient developing countries but also in developed nations.

The socio-economic and environmental impacts of water excess and shortage are such that the society increasingly urges the scientific and political community to develop appropriate policies and management plans for the prevention and mitigation of the negative effects and for the improved and more effective conservation of the environment. This requires the provision of reliable predictions of freshwater occurrence, circulation, distribution, and quality under human-induced and natural change. To be robust and credible, predictions must be underpinned by a great understanding of the hydrologic and biogeochemical cycles and their interactions with both human and natural stressors. Killeen and Abrajano (2008) and Wagener et al. (2010) argue that environmental management under global change requires new understanding of the connective and evolving role of water across a wide range of space and time scales.

Models are increasingly used to make predictions of change impacts. As phrased by Savenije (2009) a model is a hypothesis of the real world's functioning, codified in quantitative terms. He further points out that scientists and engineers use models from a different perspective. Scientists realize given the complexity of the hydrologic processes that models are poor representations of reality. The scientist's interest is focused on understanding where models are wrong, and why they are wrong. This allows the scientist to formulate possibly a better model. For the engineer the model is a tool, which he considers for the time being the best representation of reality, as the best option available for problem solving and decision making. Nowadays the hydrological community generally accepts that a good model is characterized by an "appropriate model structure", "good model performance", "small parameter and predictive uncertainty", and "applicable everywhere". The question however is what is the meaning of "appropriate", "good" "small" and "applicable"?. Practice teaches that models are primarily used as engineering tools and not as instruments for analysis. Most commercial models have fixed model structure and are rigid in their use, not likely adaptable to the requirements of a specific situation. As stated by Savenije (2009) the correct way for hydrological research is first to observe hydrological behavior, then to hypothesize the dominant mechanisms and test these mechanisms through experiments and data analysis. The dominant mechanisms can be codified in alternative model structures, which should be confronted with data to test their performance and calibrate their parameters. The best way to do this is through a top-down approach where alternative model structures are developed on the basis of physical reasoning. This makes the "one-size-fits-all" models useless for hydrological research. For research models should be completely flexible, transparent and tailor-made (Fenicia et al., 2008), whereas for engineering applications one should try to use the most appropriate model given the specific conditions and available knowledge, and define the uncertainty associated to the model prediction.

The main objective of this paper is to highlight the progress made in hydrological modeling under climate and land use change and to discuss the challenges ahead.

\section{CURRENT STATUS OF HYDROLOGIC MODELING}

In 1850, Mulvany was probably the first investigator to use mathematical modeling in a stream hydrology context. By 1892 Imbeau had conceived an event model to relate runoff to peak rainfall. 
Large scale simulation experiments were begun by the Corps of Engineers of the United States in 1953 for reservoir management. The Stanford Watershed Model (SWM) (Crawford and Linsley, 1966) is another early model integrating many sub-models including storm water and basin chemical modeling. This led to the development of the Hydrological Simulation Program-Fortran (HSPF) (Johanson et al., 1984) and other derivates. In Europe a favored comprehensive model is the Système Hydrologique Européen (SHE) (Abbott et al., 1986), which was succeeded by the MIKE SHE (Refsgaard and Storm, 1995) and SHETRAN (Bathurst et al., 1995) models. MIKE SHE is a watershed-scale physically based, spatially distributed model for water flow and sediment transport. Flow and transport processes are represented by either finite difference representations of partial differential equations or by derived empirical equations. This model claims to be able of analyzing effects of land use and climate changes on stream water quantity and quality, with consideration of groundwater interactions. Since the late 70's a large number of basin models saw daylight, among them UBC (Quick and Pipes, 1976), HBV (Bergström, 1976), Xinanjiang (Zhao et al., 1980), SWAT (Arnold et al., 1993), RORB (Dyer et al., 1994), Tank model (Sugawara, 1995), ARNO (Todini, 1996), TOPMODEL (Ambroise et al., 1996a; 1996b), GSSHA (Downer and Ogden, 2002), MOHID Land (Braunschweig et al., 2004), among many others (Singh, 1995).

Several of these models evolved to accommodate the latest data sources such as remote sensing and geographic information system data. Concerning the suitability of appropriately describing the landscape shapes, many of the models, such as MIKE SHE, use regular (rectangular) grids to account for spatial variability of basin characteristics and hydro-meteorological data, parameters and predictions; others use non-regular (still rectangular) grids, such as MODFLOW (McDonald and Harbaugh, 1988); whilst more advanced (research) models (Ivanov et al., 2004; Vivoni et al., 2004) account for spatial variability through orthogonal grids, including polygonal shaped grids and Triangular Irregular Networks (TINs). Nevertheless, only few recently developed models, such as BOUSS2D (Dehotin et al., 2011), use irregular non-orthogonal shaped grids, which, on the basis of very complex mathematical and programming costs has a great potential of being well suited for virtually any sort of (convex) landscape shapes. Whereas there is a clear tendency to make models more physically based and distributed, there is also the trend of using black box systems consisting of mathematical and statistical concepts to link input, for example rainfall, to output, for instance runoff. Commonly used techniques are regression, transfer functions, and neural networks. An alternative trend is the use of grey box modeling systems that complement the latter approach by incorporating into the modeling process certain analyses that attempt to favor some (black) model responses according to the main physics of the modeled system (Young, 2003). Notwithstanding the development of new models continues, be it at a slower rate as in the last decades of the $20^{\text {th }}$ century, recently hydrologists place increasingly emphasis on elevating the limitations to the current generation of models, and as stated by Beven a possible way to do so is on the estimation of predictive uncertainty (Beven, 1989; Binley and Beven, 1991). These authors as many others (Vázquez and Feyen, 2003; White and Chaubey, 2005; Vázquez et al., 2008) have outlined strategies for sensitivity analysis, model calibration and validation, and uncertainty estimation. These strategies are applicable to both conceptual and physical based, lumped and fully distributed hydrologic models.

Sensitivity analysis evaluates how different parameters influence a predicted output. Several methods exist to determine the sensitivity of model and input parameters. The Morris screening method (Morris, 1991) consists of a random One-factor-At-a-Time (OAT) design, which is a powerful approach widely used for sensitivity studies of individual models. One of the important advantages of this approach is its availability to investigate incremental sensitivity of each parameter on a studied quantity over its parameter range where the nonlinearity effect of each single parameter on the studied quantity can be examined. The disadvantage of this approach is that it is difficult to carry out efficient comparisons among a large number of parameter schemes. In addition, this approach is not quite efficient in identifying effects of potential parameter interactions, which is normally the case for complex hydrological models.

In order to account for the sensitivity analysis of the entire set of parameters a computational experiment consisting of a set of model runs, allowing the modification of the whole input data set according to an OAT predefined strategy, is conducted. The Latin Hypercube (LH) sampling method (Iman and Conover, 1980; Loh, 1996; Stein 1987), a variant of the standard Monte Carlo method, is a 
well-known procedure to simultaneously select random values of the parameter space. The main difference between the Monte Carlo and the Latin Hypercube sampling methods is that the latter uses a stratified sampling approach that allows a more efficient estimation of the output statistics. In the LH method the range of probable values for each uncertain input parameter is divided into ordered segments of equal probability. It means that the whole parameter space, consisting of all the uncertain parameters, is partitioned into cells having equal probability, and they are sampled in such a way that each parameter is sampled once from each of its possible segments. The advantage of the LH sampling approach is that the random samples are generated from all the ranges of possible values, thus giving insight into the extremes of the probability distributions of the outputs. The Latin Hypercube One-factor-At-a-Time (LH-OAT) sensitivity analysis method combines the robustness of the LH sampling ensuring that the full range of all parameters has been sampled with the precision of an OAT design (Van Griensven, 2006). Whereas the LH-OAT is a frequently used approach by hydrologists, it is beyond the scope of this contribution to give a critical overview of the multitude of existing methods of sensitivity analysis, as described in a large number of scientific papers covering various disciplines. Whatever approach, one of the main objectives of the sensitivity analysis is reducing the number of parameters that require fitting with input-output data, as to reduce the risk of over-parameterization, especially in distributed models.

The most sensitive parameters are modified in model calibration by comparison of predicted output of interest to measured data until a defined objective function is achieved (James and Burges, 1982). A single objective function, used when only one hydrologic response (e.g. discharge) at one calibration site in the catchment is available, consists traditionally of a simple statistical test, such as the minimization of relative error (RE), minimization of average error $(\mathrm{AE})$, minimization of the mean square error (MSE), or maximization of the Nash-Sutcliffe Efficiency Coefficient $\left(\mathrm{EF}_{2}\right)$ (Vázquez et al., 2008). To reduce the time in manual trail-and-error model calibration, the last decade a great deal of research has been dedicated into the development of automated (computer-based) calibration methods (see e.g. Gupta and Sorooshian, 1994). With respect to this, efforts have been focused on the selection of a single objective measure of the distance between the model-simulated output and the data and the selection of an automatic optimization algorithm to search for the parameter values which minimize that distance. However, practical experience with single objective functions, no matter how carefully chosen, revealed that a single objective function not adequately measures the ways in which a model fails to match the important characteristics of observed data. Furthermore, many of the latest hydrologic models simulate several of the watershed output fluxes for which measurement data are available, and all these data should be properly utilized to ensure proper model calibration (Yapo et al., 1998; Vázquez et al., 2002). Additionally, watershed hydrologic models and land-surface hydrology models, designed for coupling with general circulation models (GCM), may simulate different properties of the hydrograph and/or several energy and water fluxes and state variables. Last but not least, many of these models use distributed representations of the watershed, and state variables and output fluxes may be simulated at different locations.

As stated by several authors (e.g. Gupta et al., 1998) procedures for the proper calibration of complex distributed hydrologic models must utilize the various measurement data timeseries that provide useful information about the functioning of the system. This led to the development of a series of multiple-objective representations for model calibration, such as the Shuffled Complex Evolution (SCE), the Multi-Objective Complex Evolution (MOCOM), and the Fuzzy Multi-Objective Function method, among other methods. In general, as stated by authors such as Refsgaard (1997), Madsen and Jacobson (2001), Vázquez et al. (2002) and Vázquez et al. (2008), model calibration in a multi-objective context is performed when (i) multi-variable measurements are available, i.e. groundwater level, river runoff and other types of measurements; (ii) variables are measured at multisites, i.e. several groundwater level and runoff measurement sites distributed within the catchment; and (iii) the model simulates multi-responses, i.e. objective functions that measure various responses of the hydrological processes such as e.g. the general water balance, peak flows, and low flows. Thus, multi-objective calibration strategies should include (Refsgaard, 1997; Madsen and Jacobson, 2001; Vázquez et al., 2002; Vázquez et al., 2008): (i) a combination of graphical and statistical analyses (despite the fact that an automatic calibration procedure has been chosen); (ii) an appropriate set of model performance statistics (i.e. avoiding the use of model evaluation indexes that measure the same 
sort of model prediction error) that measure both systematic as well as random prediction errors (or residuals); (iii) multi-variable evaluation tests whenever several observed and simulated variables are considered; (iv) multi-site evaluation tests whenever distributed observations are available for the modeling; and (v) multi-temporal windows (i.e. not only the simple split-sample temporal test for calibration and validation).

Model validation is an ultimate test of whether the model and the calibrated parameters properly simulate a dataset of watershed responses that is different from the one used for model calibration. During validation the model parameters are not adjusted; however the procedures to measure the performance are similar to the ones used in the calibration procedures in that the predicted and measured values are compared (graphically and statistically) to determine if the objective function of minimizing the prediction errors is met. If the optimization of the objective function is not achieved for the validation dataset, either the calibration may be repeated and/or the model assumptions and structure revised. With respect to the latter, it is recommendable to explore and thoroughly compare different models, which might enable to identify the most appropriate model for the given watershed and objectives (Plesca et al., 2011). In their study these authors concluded that the statistical indicators clearly revealed that some of the tested model structures failed in describing the runoff generation processes, whereas other models performed quite well but failed to correctly simulate discharge minima. In addition, these authors suggest that instead of developing new modeling tools it is better to combine existing hydrological process descriptions in a general flexible framework, as for example the Catchment Modeling Framework (Kraft et al., 2010).

With the main purpose to offer decision-makers more realistic predictions many efforts have been devoted in quantifying the uncertainty on model predictions. Growing interest in this topic is evidenced by the increased amount of literature generated on this topic as mentioned by Freni et al. (2009). This in fact means that one inherently accepts that the mathematical descriptions and model structures, available today, are incapable to correctly describe the process dynamics of the phenomena hydrologists and other scientists are interested in. As such we accept that even how simple or complex the model is it still fails to predict accurately measured values due to the incompleteness in model description and structure, and errors in measured input data, measured and/or estimated model parameters and measured variables to which simulated output is compared (Lindblom et al., 2007). All of the uncertainty analysis methods produce a range of values that are likely to enclose the true value of a specific simulated variable. Lower uncertainty is connected with stricter uncertainty bands, while larger bands are caused by highly uncertain models. Using the concept of uncertainty, the better model is the one that is able to correctly simulate a specific variable while minimizing the width of the uncertainty bands. In simple terms an uncertainty analysis takes a set of randomly chosen input variables, which can include parameter values, passes them through a model or transfer function to obtain the distributions or statistical measures of the resulting outputs. The output distributions are then used to describe the range of potential outputs of the system at some probability level, or to estimate the probability that the output will exceed a specific threshold or performance measure target value. Implicit in any uncertainty analysis are the assumptions that statistical distributions for the input values are correct and that the model is a sufficiently realistic description of the processes taking place in the system. Similarly, uncertainty on the model prediction caused by errors in the model structure can be defined.

Most known methods to define the uncertainty on model predictions are the Bayesian Monte Carlo, the pseudo Bayesian Monte Carlo and the Generalized Likelihood Uncertain Estimation (GLUE) approach. The Bayesian method expresses uncertainties in the model input and parameters in terms of probability. Uncertainties in this method are evaluated starting from prior probability distributions, which represent the historical or expertise information. The GLUE method (Beven, 1993; Binley and Beven, 1991) does not use any objective function to be minimized (or maximized), but performance of different parameter sets is derived from indices of goodness-of-fit (likelihood measure). Similar to other Bayesian and pseudo-Bayesian methods, the GLUE method is based on a large number of Monte Carlo simulations, in which the random sampling of individual parameters from probability distributions is used to determine a set of parameter values. Parameters sets are then compared with respect to their ability to reproduce available observations. An example of the $\mathrm{R}$ code 
to perform a Generalized Likelihood Uncertainty Estimation (GLUE) on a hydrological model is freely available on the following website:

http://rwiki.sciviews.org/doku.php?id=guides:tutorials:hydrological_data_analysis:glue\&s=glue.

Research, however, revealed that in the case of poor parameter identifiablility, the conceptual advantage of the estimation of parameter distributions and the use of prior knowledge make the Bayesian approach more recommendable. Anyhow, the calculation of uncertainties or confidence limits using several possible re-sampling procedures has become a very useful tool for evaluating model reliability (Hanna, 1989; Omlin and Reichert, 1999).

In conclusion, even in practical applications it is of utmost importance that models before operational use are strictly subjected to a sensitivity analysis, calibration and validation, and that the confidence band on model predictions is defined. The primary objective of these set of analyses is to obtain a realistic assessment of the confidence one can place on the predictions of the model used. Quantification of the uncertainty is vital for a meaningful application of the model, in particular when models are applied for scenario assessment. Whereas in the context of investigation it is becoming a common practice to fully test models, in practical applications model codes are often selected among existing generic modeling systems without verification for the particular type of application in question, primarily by the lack of: expertise, financial resources and sufficient catchment information. This of course results often in the production of unreliable simulations and the formulation of claims on the validity of models and the need for rigorous test schemes. In order to assist users with the correct conduct of model testing and uncertainty evaluation it is highly desirable that the scientific community develops user-friendly frameworks on how model sensitivity, calibration and validation, and the calculation of the confident bands on the predictions should be conducted (Wei et al., 2007; Vázquez et al., 2009).

Further, operational use of a model may implicate that the whole described modeling process, including the conceptualization of the modeled system and the resulting model structure, are revised and repeated so that a better (i.e. more robust) operational tool is achieved for prediction of the system status under external impulses.

\section{PROGRESS IN MODELING HYDROLOGICAL CONSEQUENCES OF CLIMATE AND LAND USE CHANGE}

\subsection{Progress in modeling hydrological consequences of climate change}

The simulation of the hydrological consequences of climate and land use change is receiving the last decades increasing attention, both from the hydrology and land-surface modeling communities. Quantification of the effects of climate change consists according to Xu et al. (2005) of the following 3 steps: (i) the use of general circulation models (GCMs) to provide future global climate scenarios under the effect of increasing greenhouse gases; (ii) the use of downscaling techniques for downscaling the GCM output to the scales compatible with the study area of interest; and (iii) the use of hydrological models to simulate the effects of climate change on the hydrological response of the study area. Xu et al. (2005) offer in their paper a discussion on the progress and improvements made in the above mentioned three steps.

Most GCMs, used to generate projections of future climate change, operate on large spatial scales; a common resolution of regional climate models is 50 to $100-\mathrm{km}$ or 0.5 to 1 degree latitude, and are typically run in model time steps on the order of half an hour to one hour. Owing to their coarse horizontal resolution, GCMs are not well-suited to simulate sub-grid, mesoscale hydroclimatologic processes, nor can they provide sufficient detail in the spatial patterns of temperature and precipitation in areas of complex topography and land use. Although it is possible to run a full GCM at finer resolution, one should be aware that the model would take much longer to complete a simulation, in which case either a very powerful computer (e.g. the Earth Simulator in Japan, Tetsuya, 2004) or a much shorter simulation period (e.g. 5 years) is required. A better alternative, according to Christensen et al. (2007) and Fowler et al. (2007), is dynamic downscaling by means of Regional 
Climate Models (RCM) nested within a GCM. Doing so has important advantages over GCM-based scenarios as the physical processes are represented at a higher resolution. As mentioned by Dankers and Feyen (2008) the horizontal resolution of RCM simulations increased considerably and now approaches a level that allows a realistic simulation of the amount and intensity of precipitation at the scale of river basins and small catchments. Kay et al. (2006) used simulations from the RCM HadRM3 with a horizontal resolution of $25 \mathrm{~km}$ as direct input into a catchment-based rainfall-runoff model, resulting in relatively good estimates of the flood frequency in 15 small catchments across Great Britain. Graham et al. (2007) used the results of seven different RCM simulations, with spatial resolutions ranging from 25 to $50 \mathrm{~km}$, as input into a hydrological model of the Lule River Basin in Sweden. For the Upper Danube Basin, Dankers et al. (2007) compared very high resolution $(12 \mathrm{~km})$ climatology from the RCM HIRHAM with simulations from the same model at a much lower resolution of $50 \mathrm{~km}$. The high-resolution simulation represented the orographic precipitation patterns in this area much better than the $50 \mathrm{~km}$ experiment, and also showed more realistic extreme precipitation levels. When used to drive a hydrological model to simulate river flows, the $12 \mathrm{~km}$ climate simulation mostly resulted in realistic extreme discharge levels of the Upper Danube, although in some sub-basins there were large discrepancies with the observations. Differences with the $50 \mathrm{~km}$ experiment decreased with increasing catchment size (Dankers et al., 2007). Following Graham et al. (2007) RCMs are very useful, although one ought to be aware of potential precipitation biases.

Statistical downscaling refers to statistical techniques relating large scale climate variables (e.g. grid box rainfall and pressure) and the actual rainfall measured at one particular rain-gauge. Inherently the approach assumes that the relationship will always be the same at one particular rain-gauge, and is determined for current climate requiring the availability of a sufficient long timeseries of rainfall and temperature data. On the basis of this relationship, the GCM projections of future climate can then be used for predicting how the rainfall measured at the rain-gauge will change in the future. Alternative methods to statistical downscaling techniques are multivariate stochastic and decision support techniques (Stehlik and Bárdossy, 2002; Hay and Clark, 2003; Makropoulos and Butler, 2004). Statistical DownScaling Model (SDSM) is an example of a Windows-based decision support tool for the rapid development of single-site ensemble scenarios of daily weather variables under current and future regional climate forcing (Wilby et al., 2002). An educative web site in this regard is the ENSEMBLES downscaling portal, a user-friendly GRID-based tool for GCM post-processing and downscaling, the result of a European Commission funded project, coordinated by the Hadley Centre for Climate Prediction and Research at the UK Meteorological Office integrating the expertise of 66 institutes (http://www.cru.uea.ac.uk/projects/ensembles/ScenariosPortal/ index.htm). It allows users to choose a statistical downscaling method and produce high-resolution predictions either using as predictors observational datasets already mounted on the server or data uploaded by the user. In this portal, GCM forecasts (seasonal-to-decadal and climate change) are downscaled to local stations or uniform observation grids using any of the available downscaling algorithms. This process is performed from a web browser following three steps: predictor selection, predictand selection and downscaling method. The portal also includes a data access tool for reanalysis, GCM and observed data sets.

Many climate change experiments have been performed with GCMs, also in Latin America (Parry et al., 2007). There have been a number of such exercises for South America using an array of GCM scenarios (HADCM3, ECHAM4, GFDL, CSIRO, CCC, etc.), usually for SRES (Special Report on Emission Scenarios, http://sedac.ciesin.columbia.edu/ddc/sres/) emissions scenarios A2 and B2, more in particular for southern South America (Bidegain and Camilloni, 2004; Nuñez et al., 2005; Solman et al., 2005), Brazil (Marengo et al., 2004), Colombia (Eslava and Pabón, 2001; Pabón et al., 2001) and Mexico (Conde and Eakin, 2003). Each of the GCMs has their own strengths and weaknesses in terms of simulating various features, and different climate models show rather distinct patterns, even with almost opposite projections. Boulanger et al. (2006), using 10 GCMs for climate change scenarios for South America, noticed that the uncertainty of projections of precipitation are high. To circumvent this problem, Buytaert et al. (2009) used in their study 20 GCMs to predict for the period 2011-2030 climate change impacts on water resources in the tropical Andes. Instead of using just one GCM their choice to use the output of $20 \mathrm{GCMs}$ for the A1B scenario as input for a 
simple conceptual hydrological model was to assess the uncertainty propagation originating from the projections of global circulation models. A missing element in the analysis of Buytaert et al. (2009) is that they just considered one emission scenario, A1B which considers a balance across all sources. As suggested by Vidal and Wade (2008) as to encompass complete uncertainty in catchment-scale precipitation scenarios one should consider the interaction between the configuration of the GCM, the emission scenario and the downscaling method. The latter authors state that both the downscaling method and the multi-model building scheme (combination of GCMs and emission scenario) have a significant impact on the seasonal precipitation regime that might lead to quite different conclusions in impact assessments.

Whatever GCM scenario and downscaling method selected, traditionally the selected approach is tested to historical data of at least a 30-year period, and further applied to three twenty-year time slices: 2011-2030, 2041-2060, and 2071-2090. The output of the approach is then used as input to a conceptual or physically-based, lumped or distributed hydrological model to compute the impact of the selected approach. One of the largest uncertainties doing so is the lack of dynamic interaction between the soil-vegetation and the atmosphere, affecting the balances of water, energy and $\mathrm{CO}_{2}$ in the system. This led to the combination of global climate models with soil-vegetation-atmosphere transfer (SVAT) models (Sellers et al., 1986; Petropolous et al., 2009). Whereas in the beginning for reason of simplicity the SVAT models consisted of simple bucket type of models, nowadays they have been replaced by more physically-based SVAT models that provide better predictions of the vertical water, energy and $\mathrm{CO}_{2}$ distribution at each grid point and time interval. Parallel to this evolution, the spatial discretization and the simultaneous developments in computer capacities made it possible that information of satellite images is increasingly used as input and for testing output, and that many more model runs can be made facilitating and reducing the cost of the number of scenario runs.

\subsection{Progress in modeling hydrological consequences of land use change}

Land use and land cover changes are additionally to climate change one of the main human induced activities altering the quantity and quality of a hydrological system (Calder, 1993; Tong and Liu, 2006; Wang et al., 2008). Many studies analyzed land use change impact at catchment scale (e.g. Bronstert et al., 2002; Fohrer et al., 2001; Hundecha and Bardossy, 2004; Ott and Uhlenbrook, 2004) or on the hydrological response of changes in vegetation cover (Bahremand et al., 2006; Bosch and Hewlett, 1982; Brown et al., 2005; Hornbeck et al., 1993; Robinson et al., 2003). In traditional applications of spatially distributed hydrological models, the land use input is pre-composed and taken as fixed. It does not change during the simulation period. This means that the vegetation cover (vegetation types, or vegetation development states; represented in the model by, for instance, the leaf area index (LAI) and/or the root depth) does not vary according to the water availability. The common method is to change the land use maps (land use change scenario) over time to predict the impact on water availability under the assumption that the water demand for vegetation development is satisfied under any condition. Niehoff et al. (2002) used the land use change modeling kit (LUCK) in conjunction with a modified version of the physically based hydrological model WaSiM-ETH for flood prediction. Tang et al. (2005) applied the Land Transformation Model (LTM) in combination with the Long-Term Hydrologic Impact Assessment (LTHIA) model (Bhaduri et al., 2008). Lin et al. (2007) tested the generalized watershed loading functions model using predicted land use from the CLUE-S model (Verburg et al., 2002; Verburg et al., 2004). McColl and Aggett (2007) tested the hydrological model HECHMS together with the land use forecasting model What if?. Some models have been extended to cover a wider range of land use related impacts. To name a few, Jackson et al. (2009) highlighted the opportunities for ecohydrology to move from describing to predicting the consequences of human activities. Nosetto et al. (2008) constructed a framework to predict salt accumulation following vegetation change based on climatic, hydro-geological and biological factors. Engel et al. (2005) used a novel combination of sap flow measurements, local hydraulic gradients, diurnal water table fluctuations, and soil moisture measurements to determine water use characteristics of a Eucalyptus Camaldulensis plantation established in a native grassland of the Pampas. Callow and Smettem (2009) investigated 12 sub-catchments in a dryland agricultural region 
under their natural and modified (including infrastructure or not) conditions to study the influence of water collection infrastructure on hydrologic connectivity. They also studied whether manual modification of the DEM could account for the impact of these factors in the simulation of hydrologic and geomorphic processes. Ecohydrological modeling can provide information on the precise interaction between changes in the water system (e.g. water management actions) and its environment, but also needs a massive amount of measurements to support the impact analysis.

Recently Liu et al., (2011) presented a straightforward approach to evaluate the hydrological response in function of the historical land use change with application to the lower Tarim river region, China, from 1950 to present. These authors used the MIKE-SHE software for the simulation of the overland and channel flow, the evapotranspiration, the unsaturated and saturated flow, with a spatial resolution of $5 \mathrm{~km}$ and dynamically linked with the MIKE 11 model for the reconstruction of river water levels. The modeling approach using remote sensing data of the actual land use, daily based meteorological input of 10 stations and discharge records from two gauging stations for the period 2000-2001 and 2005, were used for respectively model calibration and validation. For the assessment of the hydrological response to land use change land use conditions were generated for decadal periods in the period 1950-2009 using historical land use data, land use maps and Landsat images. Liu's et al. (2011) investigation revealed that the lower availability of water resources in the lower reach of the river, caused by intensification of irrigation in the middle and upper reaches forced the farmers in the lower reach to relocate their activities upstream, resulting in an ever more drastic decline of farmland and vegetation, and desertification in the lower region. The introduction of a reservoir based emergency strategy from 2000 in an attempt to restore former conditions resulted in an expansion of farmland but at a slower rate than the decreasing trend before 2000. The investigation also illustrated that more water is required to restore the same amount of biomass than the amount of abstracted water that led to the biomass loss.

\section{CHALLENGES}

Although the last decades tremendous progress has been made in the scientific knowledge of hydrological modeling, the development of global climate change scenarios, the downscaling of the coarse output of GCMs to a grid level suitable for local and regional hydrological modeling, and the insight in the more correct use of hydrological models including the assessment of the uncertainty band on model predictions, there are still many challenges ahead requiring the attention of the scientific community. Until recently most research due to the component parts of science have been developed within disciplinary field boundaries. In the case of water, for example, meteorologists focus their attention on atmospheric phenomena affecting precipitation; hydrologists study water resources and transport on and beneath the ground; soil scientists focus on the reaction of water with weathered rocks; biogeochemists and ecologists worry about the coupled cycles of water, organic components, and nutrients; sedimentologists track water transport and deposition of soil and sediment particles; and geomorphologists are primarily concerned with the sculptering of landscapes by water. Whereas this approach served well in the past and will continue for some time, large-scale issues need a sophisticated understanding of the non-linearity of the interacting parts. The difficulty of up-scaling behavior and properties known at small scales has challenged traditional reductionism approaches, and we are only beginning to recognize the full complexity and emergent properties of larger Earth systems, such as large watersheds, regional basins, etc. A holistic understanding of the complex and dynamic Earth's surface and of its interacting parts is required if we are to make precise predictions of the future water balance for current conditions and under scenarios of changing climate and land use. This paradigm shift requires new tools and approaches, and regional-scale observations and modeling of the coupled climate-water cycle at a compatible scale.

With respect to the estimation of the hydrological impact of climate change according to Xu et al. (2005) the following challenges among others require our attention: 
(a) For the prediction of the hydrological impact of climate change, traditionally the output of GCMs, after downscaling, are used as input of an "offline"-hydrological model that does not take into account the feedback of water from soil to the atmosphere, which affects the output of GCMs. Therefore, the development of hydrological or land-surface parameterizations coupled with GCMs is recognized as one of the most promising approaches to determine the water cycle and its components at the macro-scale (Varis et al., 2004).

(b) Although the use of high-resolution regional climate models (RCMs) to a certain extent resolved the spatial and temporal scale mismatch between GCMs and hydrological models, RGMs are recognized to be good in the simulation at small scale of some variables, but according to Graham and Bergström (2001) they for example underperform in the simulation of extreme precipitation events. Given the uncertainties associated to nested high-resolution RCMs, partly due to the lack of realism of the large-scale forcing provided by GCMs, reduction of errors and improvement in parameterization of subgrid-scale processes in both GCMs and RCMs remain a priority for the climate-modeling community.

(c) Given the range of downscaling techniques and the fact that each approach has its own advantages and shortcomings, no universal method exists that works for all situations. As stated by $\mathrm{Xu}$ et al. (2005) all the downscaling methods are still very much in the development and testing stage, and require further improvement which could be obtained by comparison of the statistical downscaling approaches with meteorological limited-area models.

(d) Uncertainties in hydrological model prediction are still very large. Causes of the uncertainty are: (i) different hydrological models can give different stream flow values for a given input; (ii) hydrological models assume stationary conditions, but nevertheless they are used under changing or changed conditions; (iii) many model parameters can not be measured but must be estimated, and to reduce the bias in the estimations there is need for improved parameterization techniques; and (iv) the transferability of parameterization schemes across scales, regions and models is still an unresolved problem.

(e) Collection and testing of reliable data at various spatial and temporal cases are needed to improve our hydrological understanding. Still many regions in the world lack observed data of sufficient detail and quality. In addition, the global scale of human activities and the historically unprecedented magnitude of human induced land use and climate changes suggest that past data may not be a reliable guide to predictions in the future.

According to DeFries and Eshleman (2004) land use change for the feeding and sheltering of the growing human enterprise is one of the primary drivers of global change, and it is most probable that the trend in land use change will accelerate to satisfy demands of increasing numbers of people at higher standards of living. Research on investigating the consequences of land use change focused primarily on the effects of land use change on climate: (i) through emissions of carbon dioxide and other greenhouse gases from burning and decaying biomass (Houghton, 1995), or (ii) through altered exchanges of energy, water, and momentum between the land surface and atmosphere (Bonan, 1997); and the effects of habitat loss on biodiversity (Sala et al., 2000). Whereas the interaction between vegetative cover and hydrology on water quantity and quality received extensive attention, the consequences of anthropogenic land use change on hydrology have received little attention (Lambin et al., 2002). The consequences include changes in water demands from changing land use practices such as irrigation and urbanization, changes in water supply from altered hydrological processes of infiltration, groundwater recharge and runoff, and changes in water quality from agricultural runoff and suburban development. Understanding of these consequences requires transcending traditional boundaries between disciplines such as hydrology, ecology, geography and social sciences. Additionally, quantifying the hydrological consequences are complicated by the relative short lengths of hydrological records, the relative high natural variability of most hydrological systems, the difficulties in controlling land use changes in real catchments, the relative small number of controlled small-scale experimental studies that have been performed, and the challenges involved in extrapolating or generalizing results from such studies to other systems.

The recent progress with respect to the simulation of the hydrologic consequences of land use change can be summarized as: 
(a) The feasibility of observing land cover changes with satellite data. Landsat data are since a decade systematically collected around the world (Goward and Williams, 1997) and data from moderate-resolution sensors, such as MODIS, are freely available (Justice et al., 2002). The advantage of satellite data is that the coverage of information is extended over large areas at more frequent intervals, allowing new kinds of investigation such as the investigation of the effects of spatial patterns of land use within a watershed on hydrological processes and the modeling of large drainage basins. For example quantification of the impact of fertilizer uses on the fishery status in river systems requires the distribution of the land use within the entire river basin.

(b) The technological improvements in data collection and computing made it possible that the modeling capabilities for the evaluation and prediction of the hydrologic consequences of land use change at large scales advanced rapidly. Today satellite remote sensing offers the potential to provide extensive coverage of key variables such as precipitation, soil moisture, flooding, information on vegetation cover and vegetation change, and imperviousness, all important inputs to modern hydrologic modeling. The availability of high-resolution information resulted in that modeling of land use change evolved from simple empirical models to lumpedparameter and spatial distributed models.

(c) The collaboration among scientists from different disciplines is gaining acceptance - though still problematic - as to be able of addressing complex global environmental issues (Steffen et al., 2003).

The main challenges with respect to land use change is to get a clear understanding of the interactions between land use change and hydrologic processes and this at various spatial and temporal scales. Research focused on the understanding of these interactions will provide valuable input to decision-making that must balance trade-offs between the positive benefits of land use change and potentially negative unintended consequences. As stated by DeFries and Eshleman (2004) such focus requires a multidisciplinary approach with a comprehensive view towards the hydrologic processes that maintain ecological health and human requirements for food, water and shelter. Still there are many cases where analysts fail to see the important interactions and feedbacks that become apparent when different disciplines are working together, and by doing so often apparent anomalies in observations could be explained by looking beyond the limits of sub-disciplines.

Last but not least, according to the CUASHI Science Advisory Team ${ }^{2}$ the main hydrologic science challenges are: (i) process-based linkages and feedbacks within the water cycle as a function of environmental change; (ii) interactions between the biosphere and the water cycle; and (iii) the human dimension for water cycle interactions with respect to water availability and demand, and the propagation of anthropogenic modifications to the water cycle. With respect to the measurements and instrumentation most needed for the development of solutions to these challenges, the CUASHI survey (Robinsion et al., 2006) revealed that within the scientific community exist an overwhelming support for the following 4, out of 23, topics: (i) improving the integration between measurement and modeling methodologies; (ii) improving the spatial resolution of measurements; (iii) enhancing the scientific community's ability to take more and better measurements through distributed sensor networks; and (iv) improving the community's ability to measure and quantify the subsurface hydrology. The CUASHI survey further revealed that the most commonly recommended instrumentation are atmospheric profiles (e.g. water vapor lidar, temperature SODAR-radio acoustic sounding system (RASS)), geophysical equipment (including ground-penetration radar (GPR) and electromagnetic induction (EMI) sensors), water quality sensors, weather radar, soil moisture sensing capabilities, and atmospheric flux towers. And last but not least the respondents in the CUASHI survey pointed out that for success to occur, the required equipment need support and expertise in terms of application, deployment, and data interpretation.

\footnotetext{
${ }^{2}$ CUASHI: Consortium of Universities for the Advancement of Hydrologic Sciences, Inc., www.cuahsi.org
} 


\section{CONCLUSIONS}

Hydrology, more than ever before, evolved to a multi-disciplinary earth science. Water is connecting geology, ecology, atmosphere and society, and involves for finding solutions to water related problems sciences such as physics, chemistry, biology, mathematics, statistics, social and economic sciences. As stated hydrology requires a paradigm shift in which predictions of system behavior that are beyond the range of previously observed variability or that result from significant alterations of the physical system become the new norm. Hydrologists must become synthesists (observing and analyzing the system as a holistic entity) and analysts (understanding the functioning of individual system components). Still there are too many papers that deal with the application of an existing hydrological model, or that describe automated calibration, or that apply standard statistical methods, without much innovation. To make progress in finding solutions to the challenges cross-disciplinary integration must become a common characteristic of hydrologic research and educational methods. Not only hydrologic research must become more holistic but also the approach to primary and continuing education of hydrology must undergo a paradigm shift away from the current practice of imparting a narrow set of basic concepts and a disciplinary set of skills to engineers and scientists. This calls for the teaching of new skills, including the ability to read, observe, interpret, learning through case studies, and modeling of interacting processes such as human-nature interactions and feedbacks. The new generation of hydrologists must be trained to become analysts and synthesits, requiring dissolution of the historical separation between science and engineering. Similarly research should improve the utility of science for water managers.

\section{ACKNOWLEDGEMENTS}

This research was made possible by grants from (i) the National Secretary of Higher Education, Science, Technology and Innovation (SENESCYT, Ecuador) awarded to the first author (project SENESCYT-PROMETEO); and (ii) the United States Department of State's Bureau of Educational and Cultural Affairs (ECA) through the Fulbright Program awarded to the second author (NEXUS Program). This research was also possible by the participation of the second author in the development of project PIC-11-726 financed by the SENESCYT.

\section{REFERENCES}

Abbott, M.B., J.C. Bathurst, J.A. Cunge, P.E. O'Connell, J. Rasmussen, 1986. An introduction to the European System: Systeme Hydrologique Europeen (SHE). J. Hydrol., 87, 61-77.

Ambroise, B., K.J. Beven, J. Freer, 1996a. Towards a generalisation of the TOPMODEL concepts: topographic indices of hydrological similarity. Water Resour. Res., 32, 2135-2145.

Ambroise, B., J. Freer, K.J. Beven, 1996b. Application of a generalised TOPMODEL to the small Ringelbach catchment, Vosges, France. Water Resour. Res., 32, 2147-2159.

Arnold, J.G., P.M. Allen, G. Bernhardt, 1993. A comprehensive surface-groundwater flow model. J. Hydrol., 142, 47-69.

Bahremand, A., F. Smedt, J. Corluy, Y.B. Liu, J. Poorova, L. Velcicka, E. Kunikova, 2006. WetSpa model application for assessing reforestation impacts on floods in Margecany-Honrad watershed, Slovakia. Water Resour. Manage., 21(8)1373-1391.

Barnett, T.P., D.W. Pierce, H.G. Hidalgo, C. Bonfils, B.D. Santer, T. Das, G. Bala, A.W. Wood, T. Nozawa, A.A. Mirin, D.R. Cayan, M.D. Dettinger, 2008. Human-induced changes in the hydrology of the western United States. Science, 319, 1080-1083. 
Bathurst, J.C., J.M. Wicks, P.E. O'Connell, 1995. The $\{$ SHE/SHESED $\}$ basin scale water flow and sediment transport modelling system. In: Singh, V.P. (Ed.), Computer Models of Watershed Hydrology, Water Resource Publications, Highlands Ranch, CO, USA, 563-594.

Bergström, S., 1976. Development and application of a conceptual runoff model for Scandinavian catchtments. SMHI Report RHO 7, Norrköping, Sweden, 134 pp.

Beven, K.J., 1989. Changing ideas in hydrology. The case of physically based models. J. Hydrol., $105,157-172$.

Bhaduri, B., J.O.N. Harbor, B. Engel, M. Grove, 2008. Assessing watershed-scale, long-term hydrologic impacts of land use change using a GIS-NPS model. Sciences, 26(6), 643-658.

Bidegain, M., I. Camillloni, 2004. Performance of GCMs and climate baselines scenarios for Southeastern South America. Paper presented at Latin America \& Caribbean Assessment of Impacts and Adaptation to Climate Change (AIACC) Workshop, Buenos Aires, Argentina.

Binley, A.M., K.J. Beven, 1991. Physical-based modeling of catchment hydrology: a likelihood approach to reducing predictive uncertainty. In: Farmer, D.G., M.J. Rycroft (Eds.), Computer Modeling in the Environmental Sciences, Clarendon Press, Oxford, UK, 75-88.

Bonan, G., 1997. Effects of land use on the climate of the United States. Climatic Change, 37, 449486.

Bosch, J., J. Hewlett, 1982. A review of catchment experiments to determine the effect of vegetation changes on water yield and evapotranspiration. J. Hydrol., 55(1-4), 3-23.

Boulanger, J.-P., F. Martinez, E.C. Segura, 2006. Projection of future climate change conditions using IPCC simulations, neural networks and Bayesian statistics. Part 1: Temperature mean state and seasonal cycle in South America. Climate Dynam., 27, 233-259.

Braunschweig, F., P.C. Leitao, L. Fernandes, P. Pina, R.J.J. Neves, 2004. The object-oriented design of the integrated water modelling system MOHID. Proceedings of the XV International Conference on Computational Methods in Water Resources (CMWR XV), Vol. 2, Chapel Hill, NC, USA, 1079-1090.

Bronstert, A., D. Niehoff, G. Burger, 2002. Effects of climate and land use change on storm runoff generation : present knowledge and modeling capabilities. Hydrol. Process., 16(2), 509-529.

Brown, A.E., L. Zhang, T.A. McMahon, A.W. Western, R.A. Vertessy, 2005. A review of paired catchment studies for determining changes in water yield resulting from alterations in vegetation. J. Hydrol., 310(1-4), 28-61.

Buytaert, W., R. Célleri, L. Timbe, 2009. Predicting climate change impacts on water resources in the tropical Andes: Effects of GCM uncertainty. Geophys. Res. Letters, 36, L07406, doi: 10.1029/2008GL037048.

Calder, I.R., 1993. Hydrologic effects of land use change. In: Maidment, D.R. (Ed.), Handbook of hydrlogy, McGraw-Hill, NY, USA, 13.1-13.50.

Callow, J.N., K.R.J. Smetten, 2009. The effect of farm dams and constructed banks on hydrologic connectivity and runoff estimation in agricultural landscapes. Environ. Modell. Softw., 24(8), 959-968.

Crawford, N.H., R.K. Linsley, 1966. Digital simulation on hydrology: Stanford Watershed Model IV. Stanford University. Technical Report No. 39, Stanford University, Palo Alto, CA, USA.

Christensen, J.H., T.R. Carter, M. Rummukainen, G. Amanatidis, 2007. Evaluating the performance and utility of regional climate models: The PRUDENCE project. Climatic Change, 81, 1-6.

Conde, C., H. Eakin, 2003: Adaptation to climatic variability and change in Tlaxcala, Mexico. In: Smith, J., R. Klein, S. Huq (Eds)., Climate Change, Adaptive Capacity and Development. Imperial College Press, London, UK, 241-259.

Dankers, R., O.B. Christensen, L. Feyen, M. Kalas, A. de Roo, 2007. Evaluation of very high resolution climate model data for simulating flood hazards in the Upper Danube Basin. J. Hydrol., 347, 319-331. 
Dankes, R., L. Feyen, 2008. Climate change impact on flood hazard in Europe: An assessment based on high-resolution climate simulations. J. Geophys. Res., 113, D19105, doi:10.1029/2007JD009719.

DeFries, R., K.N. Eshleman, 2004. Land-use change and hydrologic processes: a major focus for the future. Hydrol. Process., 18, 2183-2186.

Dehotin, J., R.F. Vázquez, I. Braud, S. Debionne, P. Viallet, 2011. Modeling of hydrological processes using unstructured and irregular grids: 2D groundwater application. J. Hydrol. Eng., 16(2), 108-125.

Downer, C.W., F.L. Ogden, 2002. GSSHA User's manual: Gridded surface subsurface hydrologic analysis, Version 1.43 for WMS 6.1. ERDC Technical Report, Engineering Research and Development Center, Vicksburg, Miss., USA.

Dyer, B.G., R.J. Nathan, T.A. McMahon, I.C. O’Neill, 1994. Development of regional prediction equations for the RORB runoff routing model. Cooperative Research Centre for Catchment Hydrology, Report 94/1, 93 pp.

Engel, V., E.G. Jobbagy, M. Stieglitz, M. Williams, R.B. Jackson, 2005. Hydrological consequences of Eucalyptus afforestation in the Argentine Pampas. Water Resour. Res., 41(10), 1-14.

Eslava, J.A., J.D. Pabón, 2001: Proyecto: proyecciones climáticas e impactos socioeconómicos del cambio climático en Colombia. Meteorol. Colombiana, 3, 1-8.

Fenicia, F., H.H.G. Savenije, P. Matgen, L. Pfister, 2008. Understanding catchment behavior through stepwise model concept improvement. Water Resour. Res., 44, 1-13.

Fohrer, N., S. Haverkamp, K. Eckhardt, H.G. Frede, 2001. Hydrologic response to land use changes on the catchment scale. Phys. Chem. Earth Pt B, 26(7-8), 577-582.

Fowler, H.J., M. Ekström, S. Blenkinsop, A.P. Smith, 2007. Estimating change in extreme European precipitation using a multimodel ensemble. J. Geophys. Res., 112, D18104, doi:10.1029/2007JD008619.

Freni, G., G. Mannina, G. Viviani, 2009. Urban runoff modeling uncertainty: Comparison among Bayesian and pseudo-Bayesian methods. Environ. Model. Software, 24, 1100-1111.

Goward, S., D. Williams, 1997. Landsat and Earth system science: development of terrestrial monitoring. Photogramm. Eng. Rem. S., 63, 887-900.

Graham, L.P., S. Bergström, 2001. Water balance modeling in the Baltic Sea drainage basin Analysis of meteorological and hydrological approaches. Meteorol. Atmos. Phys., 77, 45-60.

Graham, L.P., J. Andréasson, B. Carlsson, 2007. Assessing climate change impacts on hydrology from an ensemble of regional climate models, model scales and linking methods - A case study on the Lule River Basin. Climatic Change, 81, 293-307.

Gupta, V.K., S. Sorooshian, 1994. Calibration of conceptual hydrologic models: past, present and future. In: Council of Scientific Research Integration (Eds.), Trends in Hydrology - Research Trends, Trivandrum, India, 329-346.

Gupta, H.V., S. Sorooshian, P.O. Yapo, 1998. Towards improved calibration of hydrologic models: multiple and non-commensurable measures of information. Water Resour. Res., 34(4), 751-763.

Hanna, S.R., 1989. Confidence limits for air quality model evaluations, as estimated by bootstrap and jackknife resampling methods. Atmos. Environ., 23(6), 1385-1398.

Hay, L.E., M.P. Clark. 2003. Use of statistically and dynamically downscaled atmospheric model output for hydrologic simulations in three mountainous basins in the western United States. $J$. Hydrol., 282, 56-75.

Hornbeck, J., M. Adams, E. Corbett, E. Verry, J. Lynch, 1993. Long-term impacts of forest treatments on water yield: a summary for northeastern USA. J. Hydrol., 150(2-4), 323-344.

Houghton, R.A., 1995. Land use change and the carbon cycle. Global Change Biology, 1, 275-287.

Hundecha, Y., A. Bardossy, 2004. Modeling the effect of land use changes on the runoff generation of a river basin through parameter regionalization of a watershed model. J. Hydrol., 292(1-4), 281295. 
Iman, R.L., W.J. Conover, 1980. Small sample sensitivity analysis techniques for computer models, with an application to risk assessment. Communications in Statistics, Part A. Theory and Methods, 17, 1749-1842.

Imbeau, M.E., 1892. La Durance: Regime. Crues et inundations. Ann. Ponts Chausses Mem. Doc. Ser., 3(1), 5-18.

Ivanov, V.Y., E.R. Vivoni, R.L. Bras, D. Entekhabi, 2004. Catchment hydrologic response with a fully distributed triangulated irregular network model. Water Resour. Res., 40(11), 10.1029/2004WR003218.

Jackson, R.B., E.G. Jobbágy, M.D. Nosetto, 2009. Ecohydrology in a human-dominated landscape. Ecohydrol., 2(3), 383-389.

James, L.D., S.J. Burges, 1982. Selection, calibration and testing of hydrologic models. In: Haan, C.T. et al. (Ed.), Hydrologic modeling of small watersheds. ASAE Monograph, St. Joseph, Michigan, 437-472.

Johanson, R.C., J.C. Imhoff, J.L. Kittle, A.S. Donigan, 1984. Hydrological simulation programFortran (HSPF): Users Manual for Release 8.0. EPA-600/3-84-006, Environmental Protection Agency, Athens, GA, USA, 767 pp.

Justice, C.O., J.R.G. Townshend, E.F. Vermote, E. Masouka, R.E. Wolfe, S. Saleous, D.P. Roy, J.T. Morisette, 2002. An overview of MODIS land data processing and product status. Rem. S. Environ., 83, 3-15.

Kay, A.L., R.G. Jones, N.S. Reynard, 2006. RCM rainfall for UK flood frequency estimation. I. Method and validation, J. Hydrol., 318, 151-162.

Killeen, T.L., T. Abrajano, 2008. Understanding the triple point. Elements, 298.

Kraft, P., K.B. Vaché, H.-G. Frede, L. Breuer, 2010. A hydrological programming language extension for integrated catchment models. Environ. Model. Software, doi:10.1016/j.envsoft.2010.12.009.

Lambin, E.F., X. Baulies, N.E. Bockstael, G. Fischer, T. Krug, R. Leemans, E.F. Moran, R. Rindfuss, Y. Sato, D.L. Skole, B.L. Turner II, C. Vogel, 2002. Land-use and land-cover change implementation strategy. IGBP Report No. 48 and IHDP Report No. 10, Louvain-la-Neuve, Belgium.

Lin, Y.P., N.M. Hong, P.J. Wu, C.J. Lin, 2007. Modeling and assessing land use and hydrological processes to future land use and climate change scenarios in water shed land use planning. Environ. Geol., 53(3), 623-634.

Lindblom, E., S. Ahlman, P.S. Mikkelsen, 2007. Uncertainty in model-based prediction of copper loads in stormwater runoff. Water Sci. Technol., 56(6), 11-18.

Liu, T., H. Fang, P. Willems, A.M. Bao, X. Chen, F. Veroustraete, Q.H. Dong, 2011. Historical land use analysis for the lower Tarim river region in China. Hydrol. Process. (submitted), 16 pp.

Loh, W.L., 1996. On Latin Hypercube Sampling. Annals of Statistics., 24(5),2058-2080.

Madsen, H., T. Jacobson, 2001. Automatic calibration of the MIKE SHE integrated hydrological modelling system. 4th DHI Software Conference, 6-8 June, Scanticon Conference Centre, Helsingør, Denmark.

Makropoulos, C., D. Butler, 2004. Spatial decisions under uncertainty: Fuzzy inference in urban water management, J. Hydroinform., 6(1), 3-18.

Marengo, J.A., W. Soares, C. Saulo, M. Nicolini, 2004. Climatology of the low level jet east of the Andes as derived from the NCEP NCAR re-analyses. J. Climate, 17, 2261-2280.

McColl, C., G. Aggett, 2007. Land use forecasting and hydrologic model integration for improved land use decision support. J. Environ. Manage., 84(4), 494-512.

McDonald, M.G., A.W. Harbaugh, 1988. A modular three-dimensional finite difference ground-water flow model. US Geology Survey Techniques of water-ressources investigations, Book 6.

Morris, M.D., 1991. Factorial sampling plans for preliminary computational experiments. Technometrics, 33, 161-174. 
Mulvany, T.J., 1850. On the use of self registering rain and flow gauges. Proc. Institute Civ. Eng., 4(2), 1-8.

Niehoff, D., U. Fritsch, A. Bronstert, 2002. Land use impacts on storm runoff generation: scenarios of land use change and simulation of hydrological response in a meso-scale catchment in SWGermany. J. Hydrol., 276(1-2), 80-93.

Nosetto, M.D., E.G. Jobbágy, T. Tóth, R.B. Jackson, 2008. Regional patterns and controls of ecosysem salinization with grassland afforestation along a rainfall gradient. Global Biogeochem. Cy., 22(2), 1-12.

Nuñez M., S. Solman, M.F. Cabré, 2005. Southern South America climate in the late twenty-first century: annual and seasonal mean climate with two forcing scenarios. Taller Regional de Cambio Climático, San Pablo, Brasil.

Omlin, M., P. Reichert, 1999. A comparison of techniques for the estimation of model prediction uncertainty. Ecol. Model., 115, 45-59.

Ott, B., S. Uhlenbrook, 2004. Quantifying the impact of land use changes at the event and seasonal time scale using a process-oriented catchment model. Hydrol. Earth System Sc., 8(1), 62-78.

Pabón, J.D., I. Cárdenas, R. Kholostyakov, A.F. Calderón, N. Bernal, F. Ruiz, 2001: Escenarios climáticos para el siglo XXI sobre el territorio colombiano. Nota Técnica Interna del Instituto de Hidrología, Meteorología y Estudios Ambientales (IDEAM), Bogotá, Colombia.

Palmer, M., E. Bernhardt, E. Chornesky, S. Collins, A. Dobson, C. Duke, B. Gold, R. Jacobson, S. Kingsland, R. Kranz, M. Mappin, M.L. Martinez, F. Micheli, J. Morse, M. Pace, M. Pascual, S. Palumbi, O.J. Reichman, A. Simons, A. Townsend, M. Turner, 2004. Ecology for a crowded planet. Science, 304, 1251-1252.

Parry, M.L., O.F. Canziani, J.P. Palutikof, 2007. Technical summary in climate change: Impacts, adaptation and vulnerability. Contribution of Working Group II to the Fourth Assessment Report of the Intergovernmental Panel on Climate Change edited by Parry, M.L., O.F. Canziani, J.P. Palutikof, P.J. van der Linden, C.E. Hanson, Cambridge University Press, Cambridge, UK, 2378.

Petropoulos, G., T.N. Carlson, M.J. Wooster, 2009. An overview of the use of the SimSphere Soil Vegetation Atmosphere Transfer (SVAT) Model for the study of land-atmosphere interactions. Sensors, 9, 4286-4308.

Plesca, I., E. Timbe, J.-F. Exbrayat, D. Windhorst, P. Kraft, P. Crespo, K.B. Vaché, H.-G. Frede, L. Breuer, 2011. Model intercomparison to explore catchment functioning: Results from a remote montane tropical rainforest. Ecol. Model., doi:10.1016/j.ecolmodel.2011.05.005.

Poff, N.L., J.D. Olden, D. Merritt, D. Pepin, 2007. Homogenization of regional river dynamics by dams and global biodiversity implications. Proc. Natl. Acad. Sci.USA, 104, 5732-5737.

Quick, M.C., A. Pipes, 1976. A combined snowmelt ana rainfall runoff model. Canad. J. Civ. Engng, 3(3), 449-460.

Refsgaard, J.C., 1997. Parameterisation, calibration and validation of distributed hydrological models. J. Hydrol., 198, 69-97.

Refsgaard, J.C., B. Storm, 1995. MIKE SHE. In: Singh, V.P. (Ed.), Computer models of watershed hydrology, Water Resources Publications, Highlands Ranch, CO, USA, 809-846.

Robinson, M., A.-L. Cognard-Plancq, C. Cosandey, J. David, P. Durand, H.-W. Führer, R. Hall, M.O. Hendriques, V. Marc, R. McCarthy, M. McDonnell, C. Martin, T. Nisbet, P. O'Dea, M. Rodgers, A. Zollner, 2003. Studies of the impact of forests on peak flows and baseflows: a European perspective. Forest Ecol. Manag., 186(1-3), 85-97.

Rodell, M., I. Velicogna, J.S. Famiglietti, 2009. Satellite-based estimates of groundwater depletion in India. Nature, 460, 999-1002.

Sala, O.E., F.S.I. Chapin, J.J. Armesto, E. Berlow, J. Bloomfield, R. Dirzo, E. Huber-Sanwald, L.F. Huenneke, R.B. Jackson, A. Kinzig, R. Leemans, D.M. Lodge, H.A. Mooney, M. Oesterheld, 
N.L. Poff, M.T. Sykes, B.H. Walker, D.H. Wall, 2000. Global biodiversity scenarios for the year 2100. Science, 287, 1770-1774.

Sanderson, E.W., M. Jaitech, M.A. Levy, K.H. Redford, A.V. Wannebo, G. Woolmer, 2002. The human footprint and the last of the wild. BioScience, 52, 891-904.

Savenije, H.H.G., 2009. The art of hydrology. Hydrol. Earth Syst. Sci., 13, 157-161.

Scanlon, B.R., K.E. Keese, A.L. Flint, L.E. Flint, C.B. Gaye, M. Edmunds, I. Simmers, 2006. Global synthesis of groundwater recharge in semiarid and arid regions. Hydrol. Process., 20, 3335-3370.

Sellers, P.J., Y. Mintz, Y.C. Sud, A. Dalcher, 1986. A simple biosphere model (SiB) for use within general circulation models. J. Atmosph. Sci., 43, 505-531.

Singh, V.P. (Ed.), 1995. Computer models of watershed hydrology. Water Resource Publications, Highlands Ranch, CO, USA.

Solman, S., M. Nuñez, M.F. Cabré, 2005. Escenarios regionales de cambio climático sobre el Sur de Sudamérica. Taller Regional de Cambio Climático, San Pablo, Brasil.

Steffen, W., J. Jager, D.J. Carson, C. Bradshaw (Eds.), 2003. Challenges of a changing earth. Series: Global Change, The IGBP Series, Springer, Heidelberg, Germany.

Stehlik, J., A. Bárdossy, 2002. Multivariate stochastic downscaling model for generating daily precipitation series based on atmospheric circulation. J. Hydrol., 256, 120-141.

Stein, M., 1987. Large sample properties of simulations using Latin Hypercube Sampling. Technometrics, 29(2), 143-151.

Sugawara, M., 1995. Tank model. In: Singh, V.P. (Ed.). Computer models of watershed hydrology, Water Resources Publications, Highlands Ranch, CO, USA, 165-214.

Tang, Z., B.A. Engel, P.C. Pijanowski, K.J. Lim, 2005. Forecasting land use change and its environmental impact at a watershed scale. J. Environ. Manage., 76(1), 35-45.

Tetsuya, S., 2004. The Earth Simulator: Roles and Impacts. Nuclear Physics B Proceedings Supplements, 129, 102.

Todini, E., 1996. The ARNO rainfall-runoff model. J. Hydrol., 175, 339-382.

Tong, S.T.Y., A.J. Liu, 2006. Modelling the hydrologic effects of land use change and its environmental impact at a watershed scale. J. Environ. Manage., 76(1), 35-45.

Van Griensven, A., T. Meixner, S. Grunwald, T. Bishop, M. Diluzio, R. Srinivasan, 2006, A global sensitivity analysis tool for the parameters of multi-variable watershed. J. Hydrol., 324, 10-23.

Varis, O., T. Kajander, R. Lemmela, 2004. Climate and water: From climate models to water resources management and vice versa. Climatic Change, 66, 321-344.

Vázquez, R.F., J. Feyen, 2003. Effect of potential evapotranspiration estimates on effective parameters and performance of the MIKE SHE-code applied to a medium-size catchment. $J$. Hydrol, 270(4), 309-327.

Vázquez, R.F., P. Willems, J. Feyen, 2008. Improving the predictions of a MIKE SHE catchmentscale application by using a multi-criteria approach. Hydrol. Process., 22(13), 2159-2179.

Vázquez, R.F., K. Beven, J. Feyen, 2009. GLUE based assessment on the overall predictions of a MIKE SHE application. Water Resour. Manage., 23(7), 1325-1349.

Vázquez, R.F., L. Feyen, J. Feyen, J.C. Refsgaard, 2002. Effect of grid-size on effective parameters and model performance of the MIKE SHE code applied to a medium sized catchment. Hydrol. Process., 16(2), 355-372.

Verburg, P.H., W. Soepboer, A. Veldkamp, R. Limpiada, V. Espaldon, S.S. Mastura, 2002. Modeling the spatial dynamics of regional land use: the CLUE-S model. Environ. Manage., 30(3), 391-405.

Verburg, P.H., T. Veldkamp, K. Overmars, J.P. Lesschen, K. Kok, 2004. Manual for CLUE-S model. Wageningen University, Wageningen, The Netherlands.

Vidal, J-P., S.D. Wade, 2008. Multimodel projections of catchment-scale precipitation regime. J. Hydrol., 353, 143-158. 
Vivoni, E.R., V.Y. Ivanov, R.L. Bras, D. Entekhabi, 2004. Generation of triangulated irregular networks based on hydrologic similarity. J. Hydrol. Eng., 9, 288-302.

Wagener, T., M. Sivapalan, B.L. McGlynn, 2008. Catchment classification and services. Toward a new paradigm for catchment hydrology driven by societal needs. In: Anderson, M.G. (Ed.), Encyclopedia of Hydrological Sciences, John Wiley, Chichester, UK.

Wagener, T., M. Sivapalan, P.A. Troch, B.L. McGlynn, C.J. Harman, H.V. Gupta, P. Kumar, P.S.C. Rao, N.B. Basu, J.S. Wilson, 2010. The future of hydrology: An evolving science for a changing world. Water Resour. Res., 46, 1-10.

Wang, S.F., S.Z. Kang, L. Zhang, F.S. Li, 2008. Modelling hydrological response to different land use and climate change scenarios in the Zamu River basin of northwest China. Hydrol. Process., 22(14), 2502-2510.

Wei, H., M.A. Nearing, J.J. Stone, 2007. A comprehensive sensitivity analysis framework for model evaluation and improvement using a case study of the Rangeland Hydrology and Erosion Model. Trans. ASABE, 50(3), 945-953.

White, K.L., I. Chaubey, 2005. Sensitivity analysis, calibation, and validations for a multisite and multivariable SWAT model. J. Amer. Water Resourc. Assoc., 1077-1089.

Wilby, R.L., C.W. Dawson, E.M. Barrow, 2002. SDSM - a decision support tool for the assessment of regional climate change impacts. Environ. Modell. Softw., 17, 147-159.

Xu, C.-yu, E. Widén, S. Halldin, 2005. Modeling hydrological consequences of climate change: Progress and Challenges. Adv. Atmos. Sci., 22(6), 789-797.

Yapo, P.O., H.V. Gupta, S. Sorooshian, 1998. Multi-objective global optimization for hydrologic models. J. Hydrol., 204, 83-97.

Young, P., 2003. Top-down and data-based mechanistic modelling of rainfall-flow dynamics at the catchment scale. Hydrol. Process., 17, 2195-2217.

Zhao, R.J., Y.L. Zhang, L.R. Fang, 1980. The Xinanjiang model. Hydrological Forecasting Proceedings Oxford Symposium, IASH, 129, 351-356. 